\title{
A study on the prevalence of Minor Physical Anomalies in schizophrenia and bipolar disorder and their first degree relatives: a comparative study
}

\author{
Md. Shahnawaz Zafar ${ }^{1}$, Rakesh Kumar², Avinash De Sousa \\ ${ }^{1}$ Senior Resident Doctor, Department of Psychiatry \\ ${ }^{2}$ Assistant Professor, Department of Psychiatry \\ ${ }^{1,2}$ Darbhanga Medical College and Hospital, Darbhanga. \\ ${ }^{3}$ Research Associate, Department of Psychiatry, Lokmanya Tilak Municipal Medical College, Mumbai. \\ E-mail-drrk2k1@gmail.com \\ Corresponding Author - Rakesh Kumar
}

\begin{abstract}
Introduction: Minor physical anomalies (MPAs) comprise a range of subtle, clinically and cosmetically insignificant errors in the development of morphological structures found in the eyes, ears, mouth, head, hands and feet. Minor physical anomalies (MPAs) may bear major informational value for diagnostic, prognostic, and epidemiological purposes.

Methodology: This study was conducted at Ranchi Institute Of Neuro-Psychiatry and Allied Sciences (RINPAS), Ranchi. The purpose of study was to compare the prevalence of Minor Physical Anomalies (MPAs) in schizophrenia, bipolar affective disorder (currently manic), their first-degree relatives and normal community control. Cross sectional research design was used in the present study, and the sample was selected using the non-probability purposive sampling technique.

Results: There were no significant differences found in marital status, ethnicity, religion and domicile among the five groups. A significant difference was found in employment, treatment history, past history, and family history of respondent.

Conclusion: Although MPAs are by no means specific to schizophrenia, they appear to be more prevalent among patients with schizophrenia compared to patients with other psychotic patients and their FDR. Moreover, MPAs of craniofacial region were more frequent in FDR of both schizophrenia and bipolar patients compared to respective psychotic patients and normal community controls.
\end{abstract}

Key Words: Minor Physical Anomalies (MPAs), schizophrenia, bipolar affective disorder, first degree relatives (FDR).

(Paper received $-15^{\text {th }}$ February 2017, Peer review completed $-20^{\text {th }}$ April 2017)

(Accepted $-9^{\text {th }}$ June 2017)

\section{INTRODUCTION}

The brain and craniofacial/limb features originate from the same germinal layer during early gestation, and so the postnatal presence of minor physical anomalies (MPAs) involving these physical features may be indicative of defects in prenatal neural migration and consequent brain abnormalities among individuals with psychosis. However, to date it is unknown what symptoms and characteristics MPAs may be associated with, or how these markers may reflect vulnerability among adolescents at high-risk for developing psychosis. This information is particularly vital for understanding susceptibility and informing etiological conceptualizations such as the neural diathesis-stress model [1].

The neuro-developmental model of schizophrenia proposes that both genetic and environmental factors contribute to structural and functional brain changes in the intrauterine and perinatal periods, as well as in 
childhood and early adolescence. Therefore, these changes occur well before the onset of psychotic symptoms that typically first appear in late adolescence or young adulthood. The notion that early brain insults predispose to schizophrenia is supported by findings that some patients with the disorder exhibit morphologic evidence of subtle developmental abnormalities that presumably occurred during embryogenesis [2].

Minor physical anomalies or informative morphogenetic variants are mild, clinically and cosmetically insignificant errors of morphogenesis which have a prenatal origin and may bear major informational value for diagnostic, prognostic and epidemiological purposes [3]. The presence of minor physical anomalies is a sensitive physical indicator of embryonic development. They are of value to the clinical researchers as they serve as indicators of altered morphogenesis that occurred early in gestation. Since both the central nervous system and the skin derived from the same ectodermal tissue in utero, minor physical anomalies may be external markers of abnormal brain development. Minor physical anomalies are considered to develop during the first and/or early second trimester of gestation [4-5] and represent potentially valuable indices of disturbances in early neurodevelopment. Once formed, they persist into adult life and are readily detected on visual examination of the particular body area.

\section{Minor Physical Anomalies and Schizophrenia}

Interest in MPAs in psychosis is not new. Last century, the Scottish psychiatrist Thomas Clouston [6] published evidence that palatal abnormalities (steep, narrow roofed palates) were more common in those patients he regarded as having 'adolescent insanity', a severe psychosis that he noted had a strong familial tendency. There has been considerable recent interest in Schizophrenia as a possible neurodevelopmental disorder, for which, minor physical anomalies may serve as a marker. An early study [7] found increased numbers of minor physical anomalies in schizophrenic children compared with normal controls. Several subsequent studies [8-9] have also found an increase in minor physical anomalies in Schizophrenia, often using a weighted scoring instrument based on distinguishing measures.

The neurodevelopmental hypothesis of Schizophrenia proposes that the 'lesion' responsible for Schizophrenia dates from the development of the brain in utero or in early life, rather than the time immediately preceding overt psychosis [10]. As a consequence of the widespread acceptance of this hypothesis, increased attention has been paid to potential markers of abnormal development. Subtle neurological signs have been reported in longitudinal studies of children at high risk of Schizophrenia and two large birth cohort studies have recently demonstrated that cohort members who go on to develop Schizophrenia deviate from the general population on a range of childhood cognitive and behavioural measures [11-12].

Neuropathology has also provided evidence supporting an early abnormality of brain development, at least in some cases [13]. Other modes of inquiry have included investigation of abnormalities of early general physical development, such as hand morphology and dermatoglyphic measures [14] and a range of subtle dysmorphic features grouped under the heading of minor physical anomalies. Researchers contend that minor physical anomalies represent external signs of prenatal development disruptions [15].

\section{Minor Physical Anomalies and Bipolar Affective Disorder}

Although a growing amount of evidence supports aberrant neurodevelopment in Bipolar affective disorder [16] and introduces Schizophrenia and Bipolar disorder as a disease continuum [17] research on markers of early neurodevelopment in patients with Bipolar affective disorder has not produced unequivocal findings [18]. Although a growing amount of evidence supports aberrant neurodevelopment in Bipolar affective disorder and in unipolar major depression and may introduce Schizophrenia, schizoaffective disorder, Bipolar affective disorder and major depression as a disease continuum [19].

\section{Measurement of Minor Physical Anomalies}

The minor physical anomalies assessment was guided by the methods established by Waldrop and Halverson [20]. The number of minor physical anomalies has been found to be stable over time. It should be noted that minor physical anomalies assessment was performed before any obvious signs of psychopathology (ages 11-13) and, therefore, completely blind to diagnostic outcome. 


\section{Minor physical anomalies}

In this study, the morphology of seven body region was examined with the use of scale for minor physical anomalies [21]. The different areas are under which the scale is divided are as follows:

Head: prominent occiput, prominent forehead, flat forehead, flat occiput, fine electric hair, double posterior whorl, frontal upswap.

Ear: pre-auricular tag, pre-auricular pits, primitive shape of ear, cup ears, ear lobe crease, lack of earlobe, low set ear, protruding auricle, soft and pliable ear, asymmetrical size of ear, double antihelix.

Eyes: brush-field spots, confluent eyebrow, short palpebral fissure, mongoloid slant, anti-mongoloid slant, inner epicanthic fold, hypertelorism.

Mouth: lip pits, multiple buccal frenula, furrowed tongue, large and small oral opening, abnormal philtrum, bifid uvula, large tongue, high arched plate.

Hand: Sydney line, single flexion on the $5^{\text {th }}$ finger, simian crease, unusual length of finger, clinodactyly.

Feet: partial syndactly toes $2-3$, sole crease, prominent heel, wide distance between 1 and 2 toe, nail hypoplasia)

Other: (supernumerary nipple, pigmented naevi, cafe-au-lait spots, haemangioma, short sternum, wide set nipple, acromial dimple, deep sacral dimple, hallucal abnormalities, dimple on tuberiositas tibiae, dimple on elbow.

The aim of this study was to compare the Prevalence of Minor physical anomalies in schizophrenia and bipolar affective disorder (currently manic) and their first-degree relatives.

\section{Objectives of the study -}

- To assess the frequency of minor physical anomalies in schizophrenia, bipolar affective disorder (currently manic) and their first-degree relatives.

- To compare the prevalence of minor physical anomalies in schizophrenia and their First-Degree Relatives.

- To compare the prevalence of minor physical anomalies in bipolar affective disorder (currently manic) and their first-degree relatives.

- To compare the prevalence of minor physical anomalies in schizophrenia and bipolar affective disorder (currently manic) patients.

\section{METHODOLOGY}

\section{Hypotheses}

1. There will be no significant difference in the prevalence of minor physical Anomalies in schizophrenia and their first-degree relatives.

2. There will be no significant difference in the prevalence of Minor Physical Anomalies in bipolar affective disorder patients (currently manic) and their first-degree relatives.

3. There will be no significant difference in the prevalence of minor physical anomalies in schizophrenia and bipolar affective disorder (currently manic).

\section{Study Design}

The study was a cross sectional hospital based study. The subjects were recruited for the study by the purposive sampling technique.

\section{Place of Study}

This study was carried out at Ranchi Institute of Neuro-Psychiatry and Allied Sciences (RINPAS), Ranchi, Jharkhand. This is a referral center for acute and chronic psychiatric patients within its catchment area which includes Jharkhand, Bihar, Orissa, Chhattisgarh and West Bengal. 


\section{Sample}

Patients attending the psychiatric Out Patient Department (OPD) of RINPAS meeting the inclusion and exclusion criteria for schizophrenia and bipolar affective disorder (currently manic) group were taken up for study. The sample includes patients with schizophrenia $(n=30)$ and their first-degree relatives $(n=30)$, patients with bipolar affective disorder (currently manic) $(n=30)$ and their first-degree relatives $(n=30)$. Additionally, one non-FDR normal control group was taken up $(n=30)$.

\section{Inclusion Criteria of Experimental Groups (Schizophrenia and Bipolar Affective Disorder)}

1. Patients of both the sexes meeting the ICD-10-DCR (WHO 1993) criteria for schizophrenia.

2. Patients of both the sexes meeting the ICD-10-DCR (WHO 1993) criteria for bipolar affective disorder patients (currently manic).

3. Patients between the age range of 18 years to 45 years.

4. Drug naïve and drug free patients ("drug free" is defined as off oral antipsychotic medications for a period of 4 weeks and long acting antipsychotic medications for a period of 8 weeks).

5. Consenting for participation in the study.

\section{Exclusion Criteria of Experimental Groups (Schizophrenia And Bipolar Affective Disorder)}

1. Serious medical disorder, neurological condition, head injury, epilepsy as assessed by history and examination.

2. Co-morbid major psychiatric disorder including substance use disorder (within 6 months of assessment), except tobacco.

3. Mini Mental Status Examination score of less than 24.

\section{Inclusion Criteria of FDR}

1. One of the first degree relatives of the patients of experimental groups (Schizophrenia and Bipolar affective disorder).

2. Individuals between the age range of 18 to 45 years

3. Score of GHQ-12 $\leq 2$.

4. Consenting for participation in the study.

\section{Exclusion Criteria of FDR}

1. Serious medical disorder, neurological condition, head injury, epilepsy as assessed by history and examination.

2. Ever has had any major psychiatric disorder including substance use disorder (within 6 months of assessment) (except tobacco use).

\section{Inclusion Criteria of Normal Control}

1. Individuals between the age of 18 to 45 years.

2. Score of GHQ- $12 \leq 2$.

3. Consenting for participation in the study.

\section{Exclusion Criteria of Normal Control}

1. Serious medical disorder, neurological condition, head injury, epilepsy as assessed by history and examination.

2. Has the individual Ever had any major psychiatric disorder including substance use disorder (within 6 months of assessment), except tobacco use in the participants or their first degree relatives. 


\section{Tools for Assessment}

\section{Socio-Demographic Data Sheet}

A specially designed socio demographic and clinical data sheet including basic information such as name, age, sex, religion, education, ethnicity, occupation ,Income in Rs/Year, marital status ,residence, duration of illness, age of onset of illness, treatment history, height and family history and past history of psychiatric illness.

\section{Scale for Minor Physical Anomalies [21]}

The Scale for Minor Physical Anomalies [21] was used for evaluation of minor physical anomalies, which includes 54 minor signs. All items in the Waldrop-scale except for head circumference and longer third toe were included in our list of minor physical anomalies. The scale is appropriate for use with both adult and paediatric patients. In all cases patients and their first degree relatives gave informed consent. All the items were to be scored as either absent or present.

\section{Brief Psychiatric Rating scale (BPRS) [22]}

This Scale is designed to assess psychopathology (including positive, negative, and affective psychopathology) in patients with, or suspected of having schizophrenia or other psychotic illnesses.

It is widely used and frequently revised, in its traditional form covers 18 items (somatic concern, anxiety, emotional withdrawal, conceptual disorganisation, guilt feelings, tension, mannerisms and posturing, grandiosity, depressive mood, hostility, suspiciousness, hallucinatory behaviour, motor retardation, uncooperativeness, unusual thought content, and blunted affect).

Each item is scored on a scale of 1 to 7 (not present - normal).The assessment is based on interview with the patient and with observations of the patient's behaviour over the previous 2-3 days (or on reports of the patient's behaviour from family members or care givers. The scale has a consistent factor structure corresponding to broad clinical features such as tension and uncooperativeness. The non-linearity of the total score distribution limits the scales use as a measure of change.

\section{Young Mania Rating Scale [23]}

The Young Mania Rating Scale (abbreviated YMRS) is an eleven-item, multiple-choice diagnostic questionnaire which psychiatrists use to measure the severity of currently manic episodes in children and adolescents between the ages of 5 and 17. It was first published in 1978.

The scale was originally developed for use in the evaluation of adult patients who were suffering from bipolar disorder, but has since been modified for use in paediatric patients. A similar scale was then developed to allow clinicians to interview parents about their children's symptoms, in order to ascertain a better diagnosis of mania in children. Clinical studies have demonstrated the effectiveness of the parent version of the scale.

\section{Global Assessment of Functioning (GAF) [24]}

The Global Assessment of Functioning (GAF) is a numeric scale (0 through 100) used by mental health clinicians and physicians to subjectively rate the social, occupational, and psychological functioning of adults, e.g., how well or adaptively one is meeting various problems-in-living. GAF levels are commonly used by the Veterans Benefits Administration of the United States Department of Veterans Affairs in determining the appropriate level of disability compensation to be paid to veterans who suffer from service connected psychiatric disorders. The emphasis on using the GAF score has however decreased in recent year.

\section{General Health Questionnaire (GHQ) [25]}

The GHQ is a self -administered screening test, which is sensitive to the prevalence of psychiatric disorders in individuals presenting in primary care setting and non-psychiatric clinical setting. The GHQ is not designed to detect symptoms that occur with specific psychiatric diagnoses such as psychotic disorders, 
rather provide a measure of overall psychological health or wellness. There are several version of GHQ. The shorter form of this version contain 12 items (GHQ-12).

Patients receiving outpatient treatment at RINPAS, fulfilling inclusion and exclusion criteria were taken up for study. At first written informed consent was taken and relevant socio-demographic details were documented in a specially designed proforma. Schizophrenia and bipolar patients were then assessed using Brief Psychiatric Rating Scale (BPRS) Expanded Version (4.0) and Young Mania Rating Scale (YMRS). Both the patient groups were then assessed with the Global Assessment Functioning (GAF). Both the FDR groups and normal control group were than assessed with GHQ-12. Detail physical examination was done subsequently to rule out any medical and neurological anomaly. Then Scale for Minor Physical Anomalies has been applied to each of the participants. Scores of minor physical anomalies were stratified according to their number of anomalies in each area, Mild anomaly (level 1) was defined as presence of at least one anomaly out of total anomalies of any one domain and moderate anomaly (level 2) was defined as presence of at least 2 anomalies of any one domain.

\section{STATISTICAL ANALYSIS}

Statistical analysis was done using SPSS 12.0. The data collected were assessed for normality of distribution. ANOVA was used to assess the group difference among the five groups of continuous sociodemographic variable (age, education, income and height). The t-test were conducted to see group difference between two psychotic groups of mean of duration of illness, age of onset, and GAF score. Chisquare tests were run to measure the difference of frequencies of discrete socio-demographic variables (like marital status, ethnicity, religion, employment etc) and level of minor physical anomaly (i.e. zero, one, and two) among five groups.

\section{RESULTS}

Table 1: Group difference of socio-demographic variables (discrete)

\begin{tabular}{|c|c|c|c|c|c|c|c|c|}
\hline Variables & Level & $\begin{array}{l}\text { Schizo- } \\
\text { phrenia } \\
(\mathrm{N}=30)\end{array}$ & $\begin{array}{c}\text { FDR of } \\
\text { Schizophr. } \\
(\mathrm{N}=30)\end{array}$ & $\begin{array}{l}\text { BPAD } \\
\text { (Manic) } \\
(\mathrm{N}=30)\end{array}$ & $\begin{array}{c}\text { FDR of } \\
\text { BPAD } \\
\text { (Manic) } \\
(\mathrm{N}=30)\end{array}$ & $\begin{array}{l}\text { Normal } \\
\text { Control } \\
(\mathrm{N}=30)\end{array}$ & $\begin{array}{l}\mathrm{X}^{2} \\
(\mathrm{df})\end{array}$ & $\mathrm{p}$ \\
\hline \multirow{2}{*}{$\begin{array}{l}\text { Marital } \\
\text { Status }\end{array}$} & Married & $19(63.3 \%)$ & $21(70 \%)$ & $22(73.3 \%)$ & $22(73.3 \%)$ & $21(70 \%)$ & \multirow{2}{*}{$\begin{array}{c}0.96 \\
(4)\end{array}$} & \multirow{2}{*}{0.92} \\
\hline & Unmarried & $11(36.7 \%)$ & $9(30 \%)$ & $8(26.7 \%)$ & $8(26.7 \%)$ & $9(30 \%)$ & & \\
\hline \multirow{2}{*}{ Ethnicity } & Tribal & $6(20 \%)$ & $6(20 \%)$ & $4(13.3 \%)$ & $4(13.3 \%)$ & $04(13.3 \%)$ & \multirow{2}{*}{$\begin{array}{c}0.86 \\
(4)\end{array}$} & \multirow{2}{*}{0.94} \\
\hline & Non tribal & $24(80 \%)$ & $24(80 \%)$ & $26(86.7 \%)$ & $26(86.7 \%)$ & $26(86.7 \%)$ & & \\
\hline \multirow{3}{*}{ Religion } & Hindu & $23(76.7 \%)$ & $23(76.7 \%)$ & $21(70 \%)$ & $21(70 \%)$ & $19(63.3 \%)$ & \multirow{3}{*}{$\begin{array}{c}1.86 \\
(8)\end{array}$} & \multirow{3}{*}{0.99} \\
\hline & Muslim & $4(13.3 \%)$ & $4(13.3 \%)$ & $05(16.7 \%)$ & $5(16.7 \%)$ & $6(20 \%)$ & & \\
\hline & Others & $3(10 \%)$ & $3(10 \%)$ & $04(13.3 \%)$ & $4(13.3 \%)$ & $5(16.7 \%)$ & & \\
\hline \multirow{2}{*}{$\begin{array}{l}\text { Employme } \\
\mathrm{nt}\end{array}$} & Employed & $17(56.7 \%)$ & $27(90 \%)$ & $25(83.3 \%)$ & $28(93.3 \%)$ & $27(90 \%)$ & \multirow{2}{*}{$\begin{array}{c}18.78 \\
(4)\end{array}$} & \multirow{2}{*}{$0.001^{*}$} \\
\hline & Unemploy. & $13(43.3 \%)$ & $3(10 \%)$ & $05(16.7 \%)$ & $2(6.7 \%)$ & $3(10 \%)$ & & \\
\hline \multirow{2}{*}{ Domicile } & Rural & $21(70 \%)$ & $23(76.7 \%)$ & $25(83.3 \%)$ & $25(83.3 \%)$ & $21(70 \%)$ & \multirow{2}{*}{$\begin{array}{l}2.99 \\
(4)\end{array}$} & \multirow{2}{*}{0.57} \\
\hline & Urban & $9(30 \%)$ & $7(23.3 \%)$ & $05(16.7 \%)$ & $5(16.7 \%)$ & $9(30 \%)$ & & \\
\hline \multirow{2}{*}{$\begin{array}{l}\text { Treatment } \\
\text { History }\end{array}$} & Untreated & $16(53.3 \%)$ & $\mathrm{N} / \mathrm{A}$ & $05(16.7 \%)$ & $\mathrm{N} / \mathrm{A}$ & N/A & \multirow{2}{*}{$\begin{array}{c}8.87 \\
(1)\end{array}$} & \multirow{2}{*}{$0.003^{*}$} \\
\hline & Treated & $14(46.7 \%)$ & N/A & $25(83.3 \%)$ & $\mathrm{N} / \mathrm{A}$ & $\mathrm{N} / \mathrm{A}$ & & \\
\hline \multirow{2}{*}{$\begin{array}{l}\text { Past } \\
\text { History }\end{array}$} & Present & 0 & N/A & $25(83.3 \%)$ & N/A & N/A & \multirow{2}{*}{$\begin{array}{c}42.86 \\
(1)\end{array}$} & \multirow{2}{*}{$0.001^{*}$} \\
\hline & Absent & $30(100 \%)$ & N/A & $05(16.7 \%)$ & N/A & N/A & & \\
\hline \multirow{2}{*}{$\begin{array}{l}\text { Family } \\
\text { History }\end{array}$} & Present & $6(20 \%)$ & N/A & $13(43.3 \%)$ & N/A & N/A & \multirow{2}{*}{$\begin{array}{c}3.78 \\
(1)\end{array}$} & \multirow{2}{*}{$0.05^{*}$} \\
\hline & Absent & $24(80 \%)$ & N/A & $17(56.7 \%)$ & N/A & N/A & & \\
\hline
\end{tabular}

(Legends: ${ }^{*} \mathrm{P} \leq 0.05 \mathrm{FDR}=$ First Degree Relative, BPAD= Bipolar Affective Disorder) 
Table 1 shows socio-demographic discrete variable details of the respondents. In marital status majority of respondent were married in all five groups. Among schizophrenia respondent $63.3 \%$ were married and $73.3 \%$ of bipolar affective patients were married. Among first degree relatives, $70 \%$ of schizophrenia first degree relatives and $73.3 \%$ of bipolar first degree relatives were married. There was no significant difference of marital status among the five groups $\left(\mathrm{X}^{2}=0.96 ; \mathrm{P}=0.92\right)$. Majority of our participants were non tribal of ethnic origin ( $80 \%$ of schizophrenia and their FDR, $86.7 \%$ of bipolar affective disorder and their FDR and $86.7 \%$ of normal control). We found no significant difference of ethnicity among the five groups $\left(\mathrm{X}^{2}=0.86 ; \mathrm{P}=0.94\right)$. In schizophrenia and their FDR $76.7 \%$ belonged to Hindu religion, $13.3 \%$ to Muslim religion, and $10 \%$ to other religion. In bipolar affective and their FDR $70 \%$ belonged to Hindu religion, $16.7 \%$ to Muslim religion, $13.3 \%$ to other religion. There was no significant difference of religious status among five group of respondents $\left(\mathrm{X}^{2}=1.86 ; \mathrm{P}=0.99\right) .56 .7 \%$ of schizophrenia patients and $90 \%$ of their FRD were employed. $83.3 \%$ bipolar affective disorder and $93.3 \%$ of their FDR were employed. In normal control group $90 \%$ were employed. This difference attained significance statistically $\left(\mathrm{X}^{2}=18.7\right.$; $\mathrm{P} \leq 0.001) .70 \%$ of schizophrenia and $76.7 \%$ of their FDR were from rural area. $83.3 \%$ of bipolar affective and their FDR were from rural area. $70 \%$ of normal control was from rural area. We found no significant difference in the domicile of the respondents $\left(\mathrm{X}^{2}=2.99 ; \mathrm{P}=0.57\right) .46 .7 \%$ of schizophrenia patient and $83.3 \%$ of bipolar affective patients were treated. There was no significant difference in terms of treatment history of respondent $\left(\mathrm{X}^{2}=8.87 ; \mathrm{P}=0.003\right)$. There was no past psychiatric history in schizophrenia patients. In bipolar affective patient $83.3 \%$ had past history of psychiatric illness. This difference between two groups reached statistical significance $\left(\mathrm{X}^{2}=42.86 ; \mathrm{P}=0.000\right)$. In $20 \%$ of schizophrenia and $43.3 \%$ of bipolar affective patient shows family history of disease. These groups were different in terms of family history of psychiatric disorder $\left(\mathrm{X}^{2}=3.87 ; \mathrm{P}=0.05\right)$.

Table 2: Group difference of socio=demographic variables (continuous)

\begin{tabular}{|l|l|l|l|l|l|l|l|}
\hline \multirow{2}{*}{$\begin{array}{l}\text { Variable } \\
\text { s }\end{array}$} & Schizophrenia & $\begin{array}{l}\text { FDR } \\
\text { Schizophrenia }\end{array}$ & $\begin{array}{l}\text { BPAD } \\
\text { (Manic) }\end{array}$ & $\begin{array}{l}\text { FDR BPAD } \\
\text { (Manic) }\end{array}$ & Normal & $\begin{array}{l}\text { F } \\
(\mathrm{df})\end{array}$ & $\mathrm{P}$ \\
\cline { 2 - 8 } & \multicolumn{7}{|c|}{ Mean \pm SD } \\
\hline $\begin{array}{l}\text { Age } \\
\text { (Years) }\end{array}$ & $30.10 \pm 8.47$ & $34.5 \pm 9.16$ & $31.5 \pm 8.04$ & $32.3 \pm 8.29$ & $31.3 \pm 7.67$ & $\begin{array}{l}1.61 \\
(4,149)\end{array}$ & 0.36 \\
\hline $\begin{array}{l}\text { Educn in } \\
\text { Years }\end{array}$ & $10.16 \pm 4.83$ & $10.7 \pm 4.45$ & $8.5 \pm 4.87$ & $9.06 \pm 4.97$ & $9.94 \pm 4.11$ & $\begin{array}{l}1.08 \\
(4,149)\end{array}$ & 0.37 \\
\hline $\begin{array}{l}\text { Income } \\
\text { Rupees } \\
\text { per } \\
\text { Year) }\end{array}$ & $35,800 \pm 54274$. & $\begin{array}{l}70,700 \pm 72,737 . \\
20\end{array}$ & $\begin{array}{l}40,400 \pm 34833 . \\
20\end{array}$ & $\begin{array}{l}45,067 \pm 27,67 \\
3.20\end{array}$ & $\begin{array}{l}46,200 \pm 258 \\
98.21\end{array}$ & $\begin{array}{l}2.6 \\
(4,149)\end{array}$ & $0.04^{*}$ \\
\hline $\begin{array}{l}\text { Height } \\
\text { (In cm) }\end{array}$ & $161.35 \pm 5.95$ & $160.55 \pm 4.78$ & $161.25 \pm 5.57$ & $160.65 \pm 5.27$ & $\begin{array}{l}158.25 \pm 5.3 \\
8\end{array}$ & $\begin{array}{l}1.62 \\
(4,149)\end{array}$ & 0.18 \\
\hline
\end{tabular}

(Legends: ${ }^{*} \mathrm{P} \leq 0.05, \mathrm{FDR}=$ First Degree Relative, $\mathrm{BPAD}=$ Bipolar Affective Disorder)

Table 2 shows socio-demographic details continuous variables of the respondents. This table shows significant difference in levels for family income $(\mathrm{F}=2.6 ; \mathrm{p}=0.04)$. The mean age during interview of schizophrenia patients was 30.10 years $(\mathrm{SD}=8.47)$ and of their first degree relative was 34.5 years $(S D=9.16$.) The mean age during interview of bipolar patient and their first degree relative were 31.5 years $(\mathrm{SD}=8.04)$ and 32.3 years $(\mathrm{SD}=8.29)$ respectively. In present study mean age of normal control respondent was 31.3 years $(\mathrm{SD}=7.67)$ and no significant difference was found among five groups $(\mathrm{F}=1.61 ; \mathrm{P}=0.36)$. As per above table mean score of education in years of schizophrenia patient was $10.16(\mathrm{SD}=4.83)$ years, and their FDR was $10.7(\mathrm{SD}=4.45)$ years. The mean score education in years of bipolar patient and their first degree relative were $8.5(\mathrm{SD}=4.87)$ years and $9.06(\mathrm{SD}=4)$ years, respectively. Similarly mean score of education in years of normal control respondent was $9.94(\mathrm{SD}=4.11)$. No significant difference was found between groups in terms of years of education $(\mathrm{F}=1.08 \mathrm{P}=0.37)$. The mean income of schizophrenia patient was Rs 35,800 (SD=54274.78), and his FDR was Rs. 70,700 ( $\mathrm{SD}=72,737.20)$ per year. . The mean 
income of bipolar patient and their first degree relative were 40,400 ( $\mathrm{SD}=34833.20)$ and 45,067 $(\mathrm{SD}=27,673.20)$ rupees respectively per year. Similarly, mean income of normal control respondent was $46,200(\mathrm{SD}=25898.21)$ rupees per year. Significant difference was found between these five groups $(\mathrm{F}=2.6$; $\mathrm{P} \leq 0.04)$. As per above table mean height of schizophrenia patient was $161.35(\mathrm{SD}=5.95) \mathrm{cm}$, and their FDR was. $160.55(\mathrm{SD}=4.78) \mathrm{cm}$. The mean height of bipolar patient and their first degree relative were $161.25(\mathrm{SD}=5.57)$ and. $160.65(\mathrm{SD}=5.27) \mathrm{cm}$ respectively. Likewise, height of normal control respondent was $158.25(\mathrm{SD}=5.38) \mathrm{cm}$. No significant difference was found among the groups $(\mathrm{F}=1.62 ; \mathrm{P}=0.18)$.

Table 3: Group difference of clinical variables

\begin{tabular}{|l|l|l|l|l|}
\hline Variables & $\begin{array}{l}\text { Schizophrenia } \\
\mathrm{M}+\mathrm{SD}\end{array}$ & $\begin{array}{l}\text { BPAD (Manic) } \\
\mathrm{M}+\mathrm{SD}\end{array}$ & $\begin{array}{l}\mathrm{t} \\
(\mathrm{df})\end{array}$ & $\mathrm{P}$ \\
\hline Duration of Illness (in years) & $5.3+4.83$ & $0.43+.22$ & $\begin{array}{l}5.53 \\
(58)\end{array}$ & 0.0001 \\
\hline $\begin{array}{l}\text { Age of Onset } \\
\text { in years) }\end{array}$ & $24.93+7.32$ & $24.8+4.46$ & $\begin{array}{l}0.08 \\
(58)\end{array}$ & 0.94 \\
\hline GAF Score & $45.87+6.47$ & $47.17+5.53$ & $\begin{array}{l}0.84 \\
(58)\end{array}$ & 0.41 \\
\hline
\end{tabular}

(Legends: ${ }^{*} \mathrm{P} \leq 0.05, \mathrm{FDR}=$ First Degree Relative, $\mathrm{BPAD}=$ Bipolar Affective Disorder)

Table 3 shows group difference in clinical variables. The mean duration of illness in schizophrenia patients was $5.3(\mathrm{SD}=4.83)$ years and bipolar affective patient was $0.43(\mathrm{SD}=0.22)$ years. No significant difference was found between groups $(\mathrm{t}=5.53 \mathrm{p}=0.000)$. Mean age of onset of schizophrenia and bipolar affective were $24.93(\mathrm{SD}=7.32)$ and $24.8(\mathrm{SD}=4.46)$ years, respectively. No significant difference was found between groups $(\mathrm{t}=0 . \mathrm{O} 8 ; \mathrm{p}=0.94)$. Mean $\mathrm{GAF}$ of schizophrenia and bipolar affective were 45.87 $(\mathrm{SD}=6.47)$ and $47.17(\mathrm{SD}=5.53)$ respectively. No significant difference was found between groups $(\mathrm{t}=0.84$ $\mathrm{p}=0.41$ ).

Table 4: Psychopathology Scores (descriptive)

\begin{tabular}{|l|l|l|}
\hline Psychopathology scores & $\begin{array}{l}\text { Schizophrenia group } \\
\text { (Mean SD) }\end{array}$ & Bipolar affective (Manic) group (Mean SD) \\
\hline BPRS & 30.27 & - \\
\hline YMRS & - & 34.68 \\
\hline
\end{tabular}

Table 4 describes psychopathology scores in two psychotic groups. The mean of total BPRS in schizophrenia group was 30.27 ( $\mathrm{SD}=3.88$.), and mean of total YMRS in bipolar affective (Manic) patient was $34.68(\mathrm{SD}=5.09)$.

Table 5 shows difference in severity level of minor physical anomalies among five groups according to the respondent response on scale for minor physical anomalies (Mehes 1988). Mild anomaly (level 1) was defined as presence of at least one anomaly out of total anomalies of any one domain and moderate anomaly (level 2) was defined as presence of at least 2 anomalies of any one domain. Mild anomaly of head domain was found in 30\% of schizophrenia and their FDR, $20 \%$ of bipolar affective disorder (Manic) and their FDR, and $13.3 \%$ of Normal participant. Moderate anomaly of head domain was found in $10 \%$ of schizophrenia and $6.7 \%$ of their FDR, and $6.7 \%$ of bipolar affective disorder (Manic). Chi-square was computed to find out the significance difference in group, and no significance difference was found in head domain of respondent $\left(\mathrm{X}^{2}=9.97 ; \mathrm{P}=0.27\right)$.

Mild anomaly of ear domain was found in $10 \%$ of schizophrenia and $23.3 \%$ of their FDR, and $10 \%$ of bipolar affective disorder and $13.3 \%$ of their FDR. Moderate anomaly of ear domain was found in $3.4 \%$ of schizophrenia FDR. There was no significance difference in frequencies of anomalies in ear domain between the five groups $\left(\mathrm{X}^{2}=12.6 ; \mathrm{P}=0.13\right)$.

Mild anomaly of eye domain was found in $10 \%$ of schizophrenia and $13.3 \%$ of their FDR, and $36.7 \%$ of bipolar affective disorder (Manic) and $43.3 \%$ of their FDR, and $10 \%$ of normal participant. This result 
shows that schizophrenia and their FDR had near normal frequency of anomaly (mild) in eye domain, but bipolar affective disorder (Manic) group had significantly more number of anomaly (mild) in this domain compared to schizophrenia and normal control groups $\left(\mathrm{X}^{2}=17.6 ; \mathrm{P}=0.001\right)$.

Table 5: Group difference of items of scale for minor physical anomalies

\begin{tabular}{|c|c|c|c|c|c|c|c|c|}
\hline Variables & $\begin{array}{l}\text { Level of } \\
\text { abnormality } \\
\text { (no. of } \\
\text { abnormality) }\end{array}$ & $\begin{array}{l}\text { Schizophrenia } \\
\mathrm{N}(\%)\end{array}$ & $\begin{array}{l}\text { FDR } \\
\text { Schizophrenia } \\
\mathrm{N}(\%)\end{array}$ & $\begin{array}{l}\text { BPAD } \\
\text { (Manic) } \\
\text { N (\%) }\end{array}$ & $\begin{array}{l}\text { FDR } \\
\text { BPAD } \\
\text { (Manic) } \\
\text { N (\%) }\end{array}$ & $\begin{array}{l}\text { Normal } \\
\text { N (\%) }\end{array}$ & $\begin{array}{l}X^{2} \\
(d f)\end{array}$ & $\mathrm{P}$ \\
\hline \multirow{3}{*}{ Head } & 0 & $18(60 \%)$ & $19(63.3 \%)$ & $22(73.3 \%)$ & $24(80 \%)$ & $26(86.7 \%)$ & \multirow{3}{*}{$\begin{array}{l}9.97 \\
(8)\end{array}$} & \multirow{3}{*}{0.27} \\
\hline & 1 & $9(30 \%)$ & $9(30 \%)$ & $6(20 \%)$ & $6(20 \%)$ & $4(13.3 \%)$ & & \\
\hline & 2 & $3(10 \%)$ & $2(6.7 \%)$ & $2(6.7 \%)$ & $0(0 \%)$ & $0(0 \%)$ & & \\
\hline \multirow{3}{*}{ Ear } & 0 & $27(90 \%)$ & $22(73.3 \%)$ & $27(90 \%)$ & $26(86.7 \%)$ & $30(100 \%)$ & \multirow{3}{*}{$\begin{array}{l}12.67 \\
(8)\end{array}$} & \multirow{3}{*}{0.13} \\
\hline & 1 & $3(10 \%)$ & $7(23.3 \%)$ & $3(10 \%)$ & $4(13.3 \%)$ & $00(0 \%)$ & & \\
\hline & 2 & $00(0 \%)$ & $1(3.4 \%)$ & $00(0 \%)$ & $00(0 \%)$ & $00(0 \%)$ & & \\
\hline \multirow{2}{*}{ Eye } & 0 & $27(90 \%)$ & $26(86.7 \%)$ & $19(63.3 \%)$ & $17(56.7 \%)$ & $27(90 \%)$ & \multirow{2}{*}{$\begin{array}{l}17.64 \\
(4)\end{array}$} & \multirow{2}{*}{$0.001^{*+}$} \\
\hline & 1 & $3(10 \%)$ & $4(13.3 \%)$ & $11(36.7 \%)$ & $13(43.3 \%)$ & $3(10 \%)$ & & \\
\hline \multirow{3}{*}{ Mouth } & 0 & $28(93.2 \%)$ & $30(100 \%)$ & $30(100 \%)$ & $30(100 \%)$ & $30(100 \%)$ & \multirow{3}{*}{$\begin{array}{l}8.11 \\
(8)\end{array}$} & \multirow{3}{*}{0.43} \\
\hline & 1 & $1(3.4 \%)$ & $00(0 \%)$ & $00(0 \%)$ & $00(0 \%)$ & $00(0 \%)$ & & \\
\hline & 2 & $1(3.4 \%)$ & $00(0 \%)$ & $00(0 \%)$ & $00(0 \%)$ & $00(0 \%)$ & & \\
\hline \multirow{2}{*}{ Hand } & 0 & $28(93.3 \%)$ & $29(96.7 \%)$ & $30(100 \%)$ & $30(100 \%)$ & $30(100 \%)$ & \multirow{2}{*}{$\begin{array}{l}5.45 \\
(4)\end{array}$} & \multirow{2}{*}{0.25} \\
\hline & 1 & $2(6.7 \%)$ & $1(3.3 \%)$ & $00(0 \%)$ & $00(0 \%)$ & $00(0 \%)$ & & \\
\hline \multirow{2}{*}{ Feet } & 0 & $29(96.7 \%)$ & $28(93.3 \%)$ & $30(100 \%)$ & $30(100 \%)$ & $30(100 \%)$ & \multirow{2}{*}{$\begin{array}{l}5.45 \\
(4)\end{array}$} & \multirow{2}{*}{0.25} \\
\hline & 1 & $1(3.3 \%)$ & $2(6.7 \%)$ & $00(0 \%)$ & $00(0 \%)$ & $00(0 \%)$ & & \\
\hline \multirow{2}{*}{ Other } & 0 & $29(96.7 \%)$ & $30(100 \%)$ & $30(100 \%)$ & $30(100 \%)$ & $30(100 \%)$ & \multirow{2}{*}{$\begin{array}{l}4.03 \\
(4)\end{array}$} & \multirow{2}{*}{0.41} \\
\hline & 1 & $1(3.3 \%)$ & $00(0 \%)$ & $00(0 \%)$ & $00(0 \%)$ & $00(0 \%)$ & & \\
\hline
\end{tabular}

(Legends: ${ }^{*} \mathrm{P} \leq 0.05, \mathrm{FDR}=$ First Degree Relative, $\mathrm{BPAD}=$ Bipolar Affective Disorder)

$3.4 \%$ of schizophrenia patients had mild and moderate level anomaly in mouth domain. Rest four groups had no anomaly in the same domain $(\mathrm{X} 2=8.11 ; \mathrm{P}=0.43)$.

Anomalies (mild) of hand and feet domain were found only in schizophrenia $(6.7 \%$ and $3.3 \%$, respectively) and their FDR (3.3\% and 6.7\%, respectively). None of the rest three groups had any anomaly in these two domains. There was no significance difference among the five groups in hand and feet domain $\left(\mathrm{X}^{2}=5.45 ; \mathrm{P}=0.25\right.$ and $\left.\mathrm{X}^{2}=5.45 ; \mathrm{P}=0.25\right)$. Mild anomaly of other domain was found only in $3.3 \%$ of schizophrenia patients. There was no significance difference among the groups in 'other' domain of scale for minor physical anomaly $\left(\mathrm{X}^{2}=4.03 ; \mathrm{P}=0.41\right)$.

\section{DISCUSSION}

Patients with schizophrenia were seen to have more MPAs in all of the anatomic zones when evaluated with the Waldrop scale. The MPA's were seen in head, eyes, ears, mouth, hands and feet, in comparison with healthy controls. This should not be taken to mean that MPAs are a necessary requirement for the development of schizophrenia. The true importance of these anomalies in relation to schizophrenia is that they may reflect the existence of a substrate that is inherited or acquired as a result of injuries that leads to disease in susceptible subjects. This idea is also supported by indirect evidence from diverse types of studies, such as family studies, suggest that the interaction between genetic predisposition and environmental stress (in utero) may increase the risk of schizophrenia and that MPAs are a marker of the occurrence of this stress in vulnerable individuals [26].

The sibling group's higher rate of total minor physical anomalies, in scores for eye and mouth regions and in specific eye, mouth and foot minor physical anomalies, is especially notable in that (with the exception 
of ear malformations) no association was found between the level or type of minor physical anomalies in the patient and in the sibling within the same family. Indeed, even the three specific minor physical anomalies that were especially increased among siblings (and also among patients) did not significantly cooccur in the patient and sibling in the same family [27].

One interpretation of this combination of results is that one or more genetic or shared environmental factors increase the risk for developing both minor physical anomalies and schizophrenia in these families at large and that the increased rate of minor physical anomalies in patients (versus siblings) signals the increased effect of such factors in those who later become schizophrenic. Furthermore, the lack of relationship between patient and siblings minor physical anomalies within the particular family could speak against a reproductive defect in the specific mothers(or fathers) that leads to replication of the same malformation in several siblings in the same family (as is seen in some families in malformation samples) [28].

As mentioned above, syndromes with both physical and behavioral characteristics that are environmentally induced (eg. fetal alcohol syndrome) and those that are genetically determined (eg. Velo Cardio Facial Syndrome) are associated with both major and minor anomalies. Within the group of disorders commonly characterized as serious mental illnesses, MPAs appear to be more common in schizophrenia. That is, elevated rates of MPAs have not been observed consistently in samples of patients with affective disorders, including bipolar disorder and major depression [29].

\section{Implications}

In the light of the current study it should be reminded that MPAs are not specific to schizophrenia and are observed in other neuro-developmental disorders such as autism, learning disabilities, and may be associated with other serious neuropsychiatric disorders such as bipolar disorders and unipolar depression [30]. Although MPAs are by no means specific to schizophrenia, they appear to be more prevalent among patients with schizophrenia compared to patients with other neuropsychiatric and/or neuro-developmental disorders. It would be interesting to see the beneficial effects of novel molecules (cognitive enhancers and nutritional supplements, for instance, polyunsaturated fatty acids especially in the context of membrane phospholipid abnormalities in schizophrenia) in improving the course and possibly to prevent the onset of schizophrenia.

\section{CONCLUSION}

Although MPAs are by no means specific to schizophrenia, they appear to be more prevalent among patients with schizophrenia compared to patients with other psychotic patients and their FDR. Moreover, MPAs of craniofacial region were more frequent in FDR of both schizophrenia and bipolar patients compared to respective psychotic patients and normal community controls.

\section{REFERENCES}

1. Weinberg SM, Jenkins EA, Marazita ML, Maher BS. Minor physical anomalies in schizophrenia: a metaanalysis. Schizophr Res 2007;89(1):72-85.

2. Fatemi SH, Folsom TD. The neurodevelopmental hypothesis of schizophrenia, revisited. Schizophr Bull 2009;35(3):528-48.

3. Gourion D, Goldberger C, Bourdel MC, Bayle FJ, Lôo H, Krebs MO. Minor physical anomalies in patients with schizophrenia and their parents: prevalence and pattern of craniofacial abnormalities. Psychiatr Res 2004;125(1):21-8.

4. Compton MT, Bollini AM, Mack LM, Kryda AD, Rutland J, Weiss PS, Bercu Z, Esterberg ML, Walker EF. Neurological soft signs and minor physical anomalies in patients with schizophrenia and related disorders, their first-degree biological relatives, and non-psychiatric controls. Schizophr Res 2007;94(1):64-73.

5. Gourion D, Goldberger C, Bourdel MC, Bayle FJ, Millet B, Olie JP, Krebs MO. Neurological soft-signs and minor physical anomalies in schizophrenia: differential transmission within families. Schizophr Res 2003;63(1):181-7. 
6. Labad A. Minor physical anomalies and schizophrenia: literature review. Actas Esp Psiquiatr 2010;38(6):365-71.

7. Guy JD, Majorski LV, Wallace CJ, Guy MP. The incidence of minor physical anomalies in adult male schizophrenics. Schizophr Bull 1983;9(4):571-82.

8. Marenco S, Weinberger DR. The neurodevelopmental hypothesis of schizophrenia: following a trail of evidence from cradle to grave. Dev Psychopathol 2000;12(3):501-27.

9. McNeil TF, Cantor-Graae E, Ismail B. Obstetric complications and congenital malformation in schizophrenia. Brain Res Rev 2000;31(2):166-78.

10. Owen MJ, O’Donovan MC, Thapar A, Craddock N. Neurodevelopmental hypothesis of schizophrenia. Br J Psychiatry 2011;198(3):173-5.

11. Chan RC, Gottesman II. Neurological soft signs as candidate endophenotypes for schizophrenia: a shooting star or a Northern star?. Neurosci Biobehav Rev 2008;32(5):957-71.

12. Chan RC, Xu T, Heinrichs RW, Yu Y, Wang Y. Neurological soft signs in schizophrenia: a meta-analysis. Schizophr Bull 2009;36(6):1089-104.

13. Harrison PJ. The neuropathology of schizophrenia: a critical review of the data and their interpretation. Brain 1999;122(4):593-624.

14. Reilly JL, Murphy PT, Byrne M, Larkin C, Gill M, O'Callaghan E, Lane A. Dermatoglyphic fluctuating asymmetry and atypical handedness in schizophrenia. Schizophr Res 2001;50(3):159-68.

15. Ismail B, Cantor-Graae E, McNeil TF. Minor physical anomalies in schizophrenia: cognitive, neurological and other clinical correlates. J Psychiatr Res 2000;34(1):45-56.

16. Sigurdsson E, Fombonne E, Sayal K, Checkley S. Neurodevelopmental antecedents of early-onset bipolar affective disorder. Br J Psychiatry 1999;174(2):121-7.

17. Maier W, Zobel A, Wagner M. Schizophrenia and bipolar disorder: differences and overlaps. Curr Opin Psychiatry 2006;19(2):165-70.

18. Arango C, Fraguas D, Parellada M. Differential neurodevelopmental trajectories in patients with early-onset bipolar and schizophrenia disorders. Schizophr Bull 2013;40(Suppl_2):S138-46.

19. Merikangas KR, Jin R, He JP, Kessler RC, Lee S, Sampson NA, Viana MC, Andrade LH, Hu C, Karam EG, Ladea M. Prevalence and correlates of bipolar spectrum disorder in the world mental health survey initiative. Arch Gen Psychiatry 2011;68(3):241-51.

20. Sivkov ST, Akabaliev VH. Minor physical anomalies in mentally healthy subjects: internal consistency of the Waldrop Physical Anomaly Scale. Am J Hum Biol 2003;15(1):61-7.

21. Hirjak D, Wolf RC, Kubera KM, Stieltjes B, Thomann PA. Multiparametric mapping of neurological soft signs in healthy adults. Brain Struct Funct 2016;221(3):1209-21.

22. Young RC, Biggs JT, Ziegler VE, Meyer DA. A rating scale for mania: reliability, validity and sensitivity. Br J Psychiatry 1978;133(5):429-35.

23. Overall JE, Gorham DR. The brief psychiatric rating scale. Psychol Rep 1962;10(3):799-812.

24. McCabe CJ, Thomas KJ, Brazier JE, Coleman P. Measuring the mental health status of a population: a comparison of the GHQ-12 and the SF-36 (MHI-5). Br J Psychiatry 1996;169(4):516-21.

25. Jones SH, Thornicroft G, Coffey M, Dunn G. A brief mental health outcome scale-reliability and validity of the Global Assessment of Functioning (GAF). Br J Psychiatry 1995;166(5):654-9.

26. McNeil TF, Cantor-Graae E. Minor physical anomalies and obstetric complications in schizophrenia. Austr NZ J Psychiatry 2000;34(2_suppl):S65-73.

27. Mittal VA, Dhruv S, Tessner KD, Walder DJ, Walker EF. The relations among putative biorisk markers in schizotypal adolescents: minor physical anomalies, movement abnormalities, and salivary cortisol. Biol Psychiatry 2007;61(10):1179-86.

28. Hata K, Iida J, Iwasaka H, Negoro H, Ueda F, Kishimoto T. Minor physical anomalies in childhood and adolescent onset schizophrenia. Psychiatr Clin Neurosci 2003;57(1):17-21.

29. Xu T, Chan RC, Compton MT. Minor physical anomalies in patients with schizophrenia, unaffected firstdegree relatives, and healthy controls: a meta-analysis. PloS One 2011;6(9):e24129.

30. Compton MT, Chan RC, Walker EF, Buckley PF. Minor physical anomalies: potentially informative vestiges of fetal developmental disruptions in schizophrenia. Int J Dev Neurosci 2011;29(3):245-50.

$$
\begin{aligned}
& * * * * * * * * * * * * * * * * * * * * \\
& \text { Acknowledgements }-\mathrm{Nil} \\
& \text { Source of Funding }-\mathrm{Nil} \\
& \text { Conflict of Interest }-\mathrm{Nil}
\end{aligned}
$$

